Brock Education

Vol 16, No. 2, 2007

\title{
Globalization and the social justice agenda for education: Moving from critique to possibilities
}

\author{
Yvette Daniel \\ University of Windsor
}

\begin{abstract}
This paper analyzes the complexities of addressing the impact of globalization on educational policy. The intent is to engage in a constructive debate about education and equity in a globalized context. Although despair is sometimes inevitable, and is, oftentimes, manifested in a continuing critique of the detrimental effects of globalization on issues of equity and social justice in education, it is not the end. It could serve as the beginning of something that is not just different and redemptive but also forward thinking. There are three parts to this paper: the first offers multiple perspectives for viewing globalization followed by an analysis of the impact on issues of equity and social justice. Lastly, an abridged version of a conceptual model adapted from Ghosh (2004) aims at renegotiating cultural space in an ever-shifting milieu is discussed as a viable possibility.
\end{abstract}

The paper presentation at the Joint Ph.D conference in beautiful Thunder Bay, in keeping with the conference theme, Globalization, Equality and Education was a wonderful opportunity to engage in, as Ball (2006) would call it, "theoretical heurism" - to underscore and analyze the complexities of addressing the impact of globalization on education in the North American context. The challenge was, not only to critique the effects that globalization has had on issues of equity and social justice, but also to forward possibilities for intervention and change using a conceptual and theoretical framework to guide future policy initiatives. Much has been written by way of critiquing the New Right (both the neo-conservative and the neo-liberal variants) agenda that has driven educational restructuring for more than two decades. It is essential to engage in a more constructive and a politically honest and challenging debate about education, efficiency and equity as we close the first decade of the new millennium.

The intent of this paper, therefore, is to argue that, although despair is sometimes inevitable, and is, oftentimes, manifested in a continuing critique of the detrimental effects that globalization has had on issues of equity and social justice in education, it is not the end. It could serve as the beginning of something that is not just

Dr. Yvette Daniel teaches graduate courses in policy and educational administration at the University of Windsor. Her research interests are in the area of policy analysis, educational administration and leadership and education in urban settings. She can be reached at ydaniel@uwindsor.ca 
different and redemptive but also forward thinking. First, a brief overview of the multiple perspectives on the contested terrain of globalization and its impact on educational policy-making in general is provided. The reader is forewarned that it is not possible to be comprehensive and discuss all the facets of the phenomenon labeled globalization in this short essay. Next, a discussion of the debate over equity and social justice issues in education in the context of globalization is entertained. Lastly, in order to underscore the argument, that it is possible to be difficult and constructive at the same time, I adopt an abridged version of the conceptual model developed by Ratna Ghosh (2004), a constructive approach for socio-cultural integration, to rethink education for citizenship and democracy in the context of the global and the local.

Globalization: The all-pervasive phenomenon

Dale (2000) argues that globalization is a promiscuous label for all sorts of phenomena. Rizvi (2000) states that a diversity of references makes it impossible to pin down a clearly defined understanding of the phenomenon of globalization that permeates the discourse of our times, befitting the post-modern conditions of our existence. It is, therefore, an essentially contested term that refers to diverse processes embracing the political, social, technological and cultural exchanges among people and states.

Kellner (2002) claims "there is no such thing as globalization per se. Rather; the concept is used to understand a heterogeneity of processes. The term is neither innocent nor neutral..." (p. 301). Every nation state and every local context is affected differently by the conditions of globalization depending upon its historical context, geography, and culture (Torres, 2002). The concept of globalization must be approached through an understanding of its three main interrelated dimensions: economic, cultural, and political (Taylor, Rivzi, Lingard, \& Henry, 1997). The transnational processes, the shortening of distances, the weakening of geopolitical borders, the links established through faster communication processes, and others have impacted all spheres of activity, economic, political, and cultural, in very complex and interrelated ways. Globalization is arguably a phenomenon that has brought about changes "in the rules of eligibility, engagement and wealth creation" (Ball, 1998, p. 119).

These changes in the rules of eligibility mean that as the multinational corporations have become more powerful, ${ }^{1}$ the ability of governments to intervene is limited. The rules of market engagement have changed from the ideals of a Keynesian capacity in which spending on social services such as health, education and welfare was perceived to be a useful economic regulation to a market model based upon costefficiency and profits that govern most institutions. However, Ball (1998) cautions us not to succumb to the myth of the powerless State and not to use the globalization thesis to explain everything; he refers to this as "globaloney" (p. 120). As capitalism becomes reorganized, the impact of new market models upon educational institutions has been far-reaching. In the new rules of wealth creation the increasing emphasis on the human side of enterprise means that all nations now look to their educational institutions for knowledge, learning, information and technological competence. All 
governments, regardless of their political persuasions look to their educational institutions to respond to the increasing competition presented by a globalized economy.

\section{The Discourse of Crisis in Education}

The rightist ideology has been most influential in the sphere of education mainly through the crisis discourse. Dale (1989) states that "the 'panic' over falling standards and illiteracy, the fear of violence in schools, and the concern with the destruction of family values and religiosity, have all had an effect" (p. 7). The fears created by this crisis discourse have been used effectively to move educational restructuring toward increased standardization and cost effectiveness. Parents, naturally being concerned about the future of their children in a milieu of increasing economic instability, were able to relate to this argument. Thus, the crisis discourse in education has had a wide electoral appeal and was used to recruit public support by creating a normative discourse that focused on improving failing standards and the need for more accountability and value for money that paved the way for much of the restructuring initiatives in education.

The emphasis on educational failure gave impetus the movement termed the rightward turn or the conservative restoration which Apple (2001) perceives as a successful struggle by the political right to form a broad-based alliance between two very different political ideologies; neo-conservatism and neo-liberalism. The neoconservative political vision is one of a strong state with a nostalgic longing for a past in which the purpose of education was clear, and everyone knew his/her place in the larger scheme of things. Neo-conservatism supports a strong standardized curriculum, calls for better educational standards and a more stringent regulation of the education system. The work of teachers is increasingly standardized and monitored closely in a move from licensed autonomy to a regulated autonomy (Apple) leading to a loss of professional authority and respect while the neoconservative educational agenda has become enmeshed in an articulation of a language of crisis (Ball, 1994).

The neo-liberal vision perceives a close relationship between education and the economy within a larger framework of global competition. This relationship influences the drive to higher educational standards and increased student testing as a preparation for entry into the marketplace. The neo-liberal perspective draws on the language of liberty, free choice, and individualism. It endorses fierce competition between schools alongside cutbacks to expenditure in education, health and social welfare services. The introduction of the market into public services has shifted more of the fiscal and moral responsibility from governments to individuals and families.

\section{Whither Art Thou, Equity?}

In a globalized milieu, education policies are driven by two main perspectives that are inspired by human capital theory ${ }^{2}$ (Vally \& Spreen, 2006). On the one hand education is seen as the main vehicle by which the nation state could maintain a foothold in international competition. On the other hand, there is an imperative of fiscal restraints and cost-containment measures. Education is considered an economic investment, and increasingly the disciplines of the market are imposed upon it in the 
form of parental choice and competition among schools. Even in compulsory education, quasi-markets have been created (Brown \& Lauder, 1996) through standardized testing, ranking and other such reform initiatives (Daniel, Edge, \& Griffith, 2002). Such congruent policies in education have emerged all across North America, the U.K., Australia, and New Zealand. Wallace (2004) states that the educational purposes have been shaped by the discourse of globalization through the consensus of policies characterized by five key elements: neo-liberalism that emphasizes market rules; new institutional economies characterized by devolution targets and incentives; performativity characterized by measurable outcomes; public choice theory; and new managerialism emphasized by efficiency and excellence. Globalization has become a legitimizing discourse and as Blackmore (2000) argues there is a globalization metanarrative that "has a discursive force in that it may produce the very effects it seeks to describe" (p. 469).

On the surface it might appear that choice and competition improve the quality of education for all. Schools are forced to compete in the market; whereby good schools will thrive while failing schools, will either be forced to improve or will be shut down thus benefiting all children. This utilitarian line of logic usually employed to defend neo-liberal ideologies and policies is flawed. "Where this involves an unequal distribution of resources, it is based upon the ability of people to profit from those resources and it is assumed that the resulting increased productivity eventually will provide benefits for all' (Olssen, Codd, \& O'Neill, 2004, p. 220). However, as the discussion below will show, the anticipated trickle-down effect is ethically wrong in terms of equity and fairness for those most disadvantaged.

\section{The Quest for Equity and Social Justice in Public Education}

The concept of social justice is open to a variety of interpretations. Olssen et al. (2004) state that there are two distinct ethical frameworks that guide educational policies: the current neo-liberal utilitarian framework and the social justice as fairness framework that that had traditionally informed education policies. In the former, education is an exchangeable commodity, the distributive principle is utility, and the major social effect is a disproportionate acquisition of resources by those in positions of advantage. In the latter, education is perceived to be a primary social good, the distributive principle is fairness, and the major social effect is redistribution of benefits by limiting choice. Figure 1 below, Ethical framework for educational policy, abridged from Olssen et al. allows us to compare and contrast these two approaches.

Bates (2006) discusses the "hierarchies of access" (p. 276) within the context of market, choice, and competition in education. In this hierarchy of access, individualism and competition for resources have replaced the principles of equity and social justice that gained prominence in policy decisions following the post-war period. Bates uses Nancy Fraser's conceptual framework of social justice and equity that is well established in the educational literature. Fraser, herself, builds upon John Rawls's conception of social justice where social justice is achieved when public resources are directed toward the socially and economically disadvantaged. Fraser, as quoted by Bates identifies three dimensions: distribution, recognition, and representation. The latter two address the relational characteristics of social justice (Gewirtz, 2001). 
Table 1: Ethical framework for educational policy (abridged from Olssen et al., 2004, p. 217)

\begin{tabular}{|l|l|l|}
\hline & Neo-liberal approach & Social Justice as Fairness \\
\hline $\begin{array}{l}\text { Primary social } \\
\text { objective }\end{array}$ & Choice & Equity \\
\hline $\begin{array}{l}\text { What is } \\
\text { distributed }\end{array}$ & $\begin{array}{l}\text { Education as a preferred } \\
\text { good }\end{array}$ & $\begin{array}{l}\text { Education as a primary } \\
\text { social good }\end{array}$ \\
\hline $\begin{array}{l}\text { Distributive } \\
\text { principle }\end{array}$ & Utility & Fairness \\
\hline $\begin{array}{l}\text { Main criterion for } \\
\text { resource } \\
\text { allocation }\end{array}$ & $\begin{array}{l}\text { Efficiency (invest to } \\
\text { maximize aggregate } \\
\text { gains) }\end{array}$ & $\begin{array}{l}\text { Need (invest to improve } \\
\text { opportunities for the least } \\
\text { advantaged }\end{array}$ \\
\hline $\begin{array}{l}\text { Major educational } \\
\text { outcome }\end{array}$ & $\begin{array}{l}\text { Increased educational } \\
\text { productivity }\end{array}$ & $\begin{array}{l}\text { Fairer distribution of } \\
\text { educational benefits }\end{array}$ \\
\hline $\begin{array}{l}\text { Major social } \\
\text { effect }\end{array}$ & $\begin{array}{l}\text { Disproportionate } \\
\text { acquisition of resources } \\
\text { by most advantaged }\end{array}$ & $\begin{array}{l}\text { Redistribution of benefits } \\
\text { by limiting choice }\end{array}$ \\
\hline
\end{tabular}

The first dimension is the mal-distribution of resources in education underscored by three basic issues of money, power, and curriculum (Martell, 2006). The focus on markets, choice, and competition has created a greater gap between schools in lower socio-economic areas and those in richer neighborhoods. In an era of fiscal restraint, it is not difficult to see that those with social, cultural, and economic capital are better able to access resources and define the curriculum for the schools their children attend. The second dimension to be redressed is misrecognition occurring through institutionalized practices of exclusion in our schools. Even as we tout the notion of inclusion in our schools, the considerably high drop-out rate in Ontario, despite improvements (28\% according to the recent King Report, Ministry of Education, 2005) is evidence of these systemic inequities. Thirdly, there is a crisis of representation manifested in institutional and systemic obstacles that leave some on the margins of schooling. Unless, these are addressed by structural reorganization that will facilitate fuller participation of all in the knowledge economy, social justice remains a distant goal.

\section{Renegotiating Cultural Space}

The impediments to attaining the objectives of social justice and equity in education largely discernible through maldistribution, misrecognition and misrepresentation delineated in the previous section continue to gain momentum in positioning education on a globalized landscape. Political will and ideology can still affect and influence equity outcomes (Blackmore, 2000). However, we cannot turn back to the post-war welfare state. Kuehn (2005) uses two tool metaphors, a wedge and a ratchet, to describe the impact of globalization that has changed public services from which there is no turning back. A wedge starts out by making a small cut in the wood, but as it is hit to go further, it splits the wood. Similarly, at first, the impact of globalization on public services in general, and education in particular is not perceived 
to be significant. However, various trade agreements, such as the GATS treaty of 1995 , force open public services toward increased privatization and to the vagaries of the market-place. The second analogy, that of the ratchet, refers to a tool that always pulls in one direction, as in a globalized economy toward liberalizing rules. In order to keep with the notion of forward thinking Torres (2002) states:

If our contemporary discussion of education is to have meaning, it must move beyond assumptions about national boundaries and goals internal to national agendas. It must address the questions raised by the globalization of the two traditional bases of formalized educational systems: governance and economies. These questions are very straightforward: Will globalization make human rights and democratic participation more universal, or will globalization redefine human enterprise as market exchanges invulnerable to traditional forms of civic governance? (p. 364)

The time has come to redefine and restructure education, beyond the conventional practices of testing, standardization, and competition to address the changing needs of an interconnected and multi-faceted new economy. Rigor and standards work alongside as our educational systems seek different ways to foster the ability to operate, collaborate, and work in diverse cultural contexts. Ratna Ghosh (2004) proposes a conceptual model that places integration at the helm of a new paradigm-"...the intelligent organization (Landier, 1995), which is characterized by pluralism and freedom, a redistribution of power so that the role of the center is to act on behalf of the parts, and being at the middle of things rather than at the top" (p. 94).

Ghosh (2004) proposes the third space model, a constructive approach characterized by a renegotiation of cultural space, and a redefinition of values in which the notions of knowledge, cultural differences, and identity are transformed. Although her model is built upon the notion of interdependency among the three NAFTA partners, I found that this model could easily be broadened to include educational systems in general. Below, I pick out key ideas from Ghosh's model to explore ways to address issues of equity and social justice, with a particular focus on the three dimensions, in an ever-changing and complex globalized world in which we live and work.

The notion of what counts as knowledge has been challenged for quite some time. However, in this model, it is not about replacing one form of knowledge with another, "but rather to validate and learn about other forms of knowledge" (Ghosh, 2004, p. 96). In acknowledging and validating diverse forms of knowledge, we begin to redress the issue of misrecognition in school practices that reproduce culturally entrenched patterns of exclusion and unwillingness to engage with others across cultural and social boundaries (Bates, 2006). This openness to interconnectedness in a networked milieu is at the forefront of transforming knowledge and learning in a globalized world.

In this model, the conceptions of identity and difference are not seen as static or rigid, but always in a state of becoming. Our identities are local, regional, and global. They are constructed at both the micro and macro levels. Ghosh (2004) argues that the 
politics of location confines people, in that the social construction of people creates hierarchies that affect their access to and success in education through misrecognition and misrepresentation that in turn affects distribution of resources. Transformation is needed in the politics of location in a globalized context in which differences are acknowledged to redress misrecognition (one of the forms of oppression in our system).

In our changing global context, the notion of quality is also contested terrain. What counts as quality and who defines it? Rigor, quality, standards are defined by the value systems that favor the dominant culture. Ghosh (2004) recommends: "Standards must be established which take the differences of cultures, knowledge, multidisciplinary ways of learning into consideration. Different languages and histories will be significant" (p. 97). Such a move would go a long way in redressing issues of misrepresentation to democratize access to knowledge and validation of different forms of knowledge in the measurement of standards.

Furthermore, in any discussion on globalization, the significance of the uses of technologies takes precedence. Interdependence among people is facilitated through information and communication networks. With regards to education, despite attempts to close the digital divide, the issue of mal-distribution is glaring, and much work needs to be done to attain equitable outcomes in our schools. There is a great variation among schools in terms of technological skills and resources that prevent certain groups from participating as full partners in a globalized economy, while others get a head start due to their ease of access to technological knowledge and ability to keep abreast of the latest innovations.

The conceptual model proposed above calls for powerful coalitions in education that connect people and places to the larger social purpose of our education system (Martell, 2006). Progressive-minded people who believe in and understand the need for a "renegotiation of cultural space and a reconceptualization of the way we think about learning systems" (Ghosh, 2004, p. 90) have to reject the human capital theory that is driving current policy changes in education. Globalization, itself, can be used effectively to form these coalitions in renegotiating cultural space in which the three basic issues of money, power, and curriculum are integrated into one platform (Martell) becoming the agenda for reform ${ }^{1}$ that gives priority to democratic processes and programs.

\section{Conclusion}

One of the main challenges of this essay is the attempt to encompass key ideas and concepts in a concise yet logical and comprehensible manner within the constraints of space and time. The intent, here, was to argue that globalization in all its forms, along with its positive and negative characteristics is very much a part of our landscape. Further, this acknowledgement should enable us to engage in forward thinking in our quest to attain social justice and equity in our educational systems. In conclusion, the multi-dimensional and complex phenomenon of globalization is hard to define. However, we know that it encompasses certain key characteristics such as interconnectedness, the rise of human capital theory, and education, as a preferred commodity that has an exchange value in a market-driven 
economy. The impact of globalization on issues of equity were analyzed, followed by a brief description of an adaptation of a conceptual model for renegotiating cultural space to address the various dimensions of equity and fairness. Globalization, thus, can become a tool for change in attempts to move away from regressive notions in which diversity and difference are treated as individual issues, in a move toward a larger vision of a globalized society in which equity, efficiency, and progress are not mutually exclusive.

\section{Endnotes}

${ }^{1} 51 \%$ of the world's largest economies are global corporations and not nation states. WalMart is bigger than the economies of 161 countries.

${ }^{2}$ Human capital theory postulates that education and training is costly, and should be considered to be an investment since it is undertaken with a view to increasing value (and personal incomes) - it becomes a value-added product by which the economy is improved. ${ }^{3}$ The reader will note that I have used the terms "restructuring" and change throughout. Reform, in my understanding, refers to a change for the better.

\section{References}

Apple, M. (2001). Educating the "right way": Markets, standards, god, and inequality. London \& New York: RoutledgeFalmer.

Ball, S. (1994). Some reflections on policy theory: A brief response to Hatcher and Troyna. Journal of Education Policy, 9(2), 171-182.

Ball, S. (1998). Big policies/small world: An introduction to international perspectives in education policy. Comparative Education, 34(2), 119-130.

Ball, S. (2006). What is policy? Texts, trajectories and toolboxes. In S. Ball (Ed.), Education, policy and social class: The selected works of Stephen J. Ball (pp. 43-53). London \& New York: Routledge.

Bates, R. (2006). Public education, social justice and teacher education. Asia Pacific Journal of Teacher Education, 34(3), 275-286.

Blackmore, J. (2000). Warning signals or dangerous opportunities? Globalization, gender and educational policy shifts. Educational Theory, 50(4), 467-486.

Brown, P., \& Lauder, H. (1996). Education, globalization and economic development. Journal of Education Policy, 11(1), 1-25.

Dale, R. (1989). The state and education policy. Philadephia: Open University Press.

Dale, R. (2000). Globalization and education: Demonstrating a "common world educational culture" or locating a "globally structured educational agenda"? Educational Theory, 50(4), 427-452.

Daniel, Y., Edge, K., \& Griffith, A. (2002). Educational research, globalization and change: Exploring issues. In C. Reynolds \& A. Griffith (Eds.), Equity and globalization in education (pp. 27-52). Calgary, AB, Canada: Detselig Enterprises.

Gewirtz, S. (2001). Rethinking social justice: A conceptual analysis. In J. Demaine (Ed.), Sociology of education today (pp. 49-64). England, UK: Palgrave.

Ghosh, R. (2004). Globalization in the North American region: Toward renegotiation of cultural space. McGill Journal of Education, 39(1), 87-101. 
Kellner, D. (2002). Globalization and new social movements: Lessons for critical theory and pedagogy. In N. Burbules \& C. Torres (Eds.), Globalization and education: Critical perspectives (pp. 299-322). New York: Routledge.

Kuehn, L. (2005, November). Resistance to making education a tradable commodity. Presentation to 'Education Forum of the People's Summit of the Americas' Mar del Plata, Argentina, November 2005. Retrieved June 10, 2006, from http://www.bctf.bc.ca/Social

Martell, G. (2006, Spring). Introduction. Education's iron cage and its dismantling in the new global order, Our schools/Our selves, Special Issue, 1-14.

Ministry of Education. (2005). The king report. Retrieved November 12, 2005, from http://www.premier.gov.on.ca/news/Product.asp?ProductID=489

Olssen, M., Codd, J., \& O’Neill, A. (2004). Education policy: Globalization, citizenship \& democracy. London: Sage.

Rizvi, F. (2000). Globalization and education: Complexities and contingencies. Educational Theory, 50(4), 419-426.

Taylor, S., Rivzi, F., Lingard, B., \& Henry, M. (1997). Educational policy and the politics of change. London \& New York: Routledge.

Torres, C. (2002). Globalization, education and citizenship: Solidarity versus markets? American Educational Research Association, 39(2), 363-378.

Vally, S., \& Spreen, C. (2006). The globalization of education policy and practice in South Africa. Our Schools, Our Selves, 15(3), 57-74.

Wallace, J. (2004). Educational purposes economicus: Globalizaton and the reshaping of educational purpose in three Canadian provinces. Canadian and International Education, 33(1), 99-117. 